\title{
Retrospective analysis of radiation exposure during endoscopic retrograde cholangiopancreatography: Critical determinants
}

\author{
Edward Kim MD ${ }^{1}$ Mark McLoughlin $\mathrm{MD}^{2}$, Eric C Lam MD², Jack Amar MD², \\ Michael Byrne $M D^{3}$, Jennifer Telford $M D^{2}$, Robert Enns $M D^{2}$
}

E Kim, M McLoughlin, EC Lam, et al. Retrospective analysis of radiation exposure during endoscopic retrograde cholangiopancreatography: Critical determinants. Can J Gastroenterol 2011;25(10):555-559.

BACKGROUND: Fluoroscopy during endoscopic retrograde cholangiopancreatography (ERCP) has a logarithmic relationship with radiation exposure, and carries a known risk of radiation exposure to patients and staff. Factors associated with prolonged fluoroscopy duration have not been well delineated.

OBJECTIVES: To determine the specific patient, physician and procedural factors that affect fluoroscopy duration.

METHODS: A retrospective analysis of 1071 ERCPs performed at two tertiary care referral hospitals over an 18 -month period was conducted. Patient, physician and procedural variables were recorded at the time of the procedure.

RESULTS: The mean duration of 969 fluoroscopy procedures was $4.66 \min$ (95\% CI 4.38 to 4.93 ). Multivariable analysis showed that the specific patient factors associated with prolonged fluoroscopy duration included age and diagnosis (both $\mathrm{P}<0.0001$ ). The endoscopist was found to play an important role in the duration of fluoroscopy (ie, all endoscopists studied had a mean fluoroscopy duration significantly different from the reference endoscopist). In addition, the following procedural variables were found to be significant: number of procedures, basket use, biopsies, papillotomy (all $\mathrm{P}<0.0001)$ and use of a tritome $(\mathrm{P}=0.004)$. Mean fluoroscopy duration (in minutes) with 95\% CIs for different diagnoses were as follows: common bile duct stones $(n=443) 5.12$ ( 3.05 to 4.07$)$; benign biliary strictures $(n=135)$ 3.94 (3.26 to 4.63$)$; malignant biliary strictures $(n=124) 5.82$ ( 4.80 to 6.85); chronic pancreatitis $(\mathrm{n}=49) 4.53$ (3.44 to 5.63); bile leak $(n=26) 3.67$ (2.23 to 5.09); and ampullary mass $(n=11) 3.88$ (1.28 to 6.48). When no pathology was found ( $n=195)$, the mean fluoroscopy time was $3.56 \mathrm{~min}$ (95\% CI 3.05 to 4.07). Comparison using $t$ tests determined that the only two diagnoses for which fluoroscopy duration was significantly different from the reference diagnosis of 'no pathology found' were common bile duct stones $(\mathrm{P}<0.0001)$ and malignant strictures $(\mathrm{P}<0.0001)$.

CONCLUSIONS: Factors that significantly affected fluoroscopy duration included age, diagnosis, endoscopist, and the number and nature of procedures performed. Elderly patients with biliary stones or a malignant stricture were likely to require the longest duration of fluoroscopy. These identified variables may help endoscopists predict which procedures are associated with prolonged fluoroscopy duration so that appropriate precautions can be undertaken.

Key Words: ERCP; Fluoroscopy time; Radiation

\author{
L'analyse rétrospective de l'exposition aux \\ radiations pendant une cholangiopancréatographie \\ endoscopique rétrograde : les déterminants \\ critiques
}

HISTORIQUE : La fluoroscopie pendant la cholangiopancréatographie rétrograde endoscopique (CPRE) a une relation logarithmique avec l'exposition aux radiations et s'associe à un risque connu d'exposition aux radiations pour les patients et le personnel. Les facteurs liés à une durée prolongée de la fluoroscopie ne sont pas bien délimités.

OBJECTIFS : Déterminer les facteurs propres aux patients, aux médecins et aux interventions qui influent sur la durée de la fluoroscopie.

MÉTHODOLOGIE :Les auteurs ont procédé à une analyse rétrospective de 1071 CPRE effectuées dans deux hôpitaux de soins tertiaires pendant une période de 18 mois. Ils ont consigné les variables liées aux patients, aux médecins et aux interventions pendant l'intervention.

RÉSULTATS : La durée moyenne des 969 interventions de fluoroscopie était de 4,66 min (95\% IC 4,38 à 4,93). L'analyse multivariable a démontré que les facteurs propres aux patients associés à une durée prolongée de la fluoroscopie incluaient l'âge et le diagnostic (tous deux $\mathrm{P}<0,0001$ ). On a constaté que l'endoscopiste jouait un rôle important dans la durée de la fluoroscopie (la durée moyenne de fluoroscopie de tous les endoscopistes à l'étude était très différente de celle de l'endoscopiste de référence). En outre, les variables d'intervention suivantes se sont révélées significatives : nombre d'interventions, utilisation du panier, papillotomie (tous $\mathrm{P}<0,0001)$ et utilisation d'un Tri-Titome $(\mathrm{P}=0,004)$. La durée moyenne de la fluoroscopie (en minutes), pour un IC de $95 \%$ pour divers diagnostics, s'établissait comme suit : calculs biliaires communs $(n=443)$ $5,12(3,05$ à 4,07); rétrécissements biliaires bénins $(\mathrm{n}=135)$ 3,94 (3,26 à $4,63)$; rétrécissements biliaires malins $(\mathrm{n}=124) 5,82$ (4,80 à 6,85); pancréatites chroniques $(n=49) 4,53 \quad(3,44$ à 5,63$)$; fuites biliaires $(n=26)$ $3,67(2,23$ à 5,09) et masses de l'ampoule $(n=11) 3,88(1,28$ à 6,48$)$. En l'absence de pathologie $(\mathrm{n}=195)$, la durée moyenne de la fluoroscopie était de 3,56 min (95\% IC 3,05 à 4,07). La comparaison au moyen des testst a déterminé que les seuls deux diagnostics pour lesquels la durée de la fluoroscopie était considérablement différente de celle du diagnostic de référence de " aucune pathologie décelée " étaient les calculs biliaires communs $(\mathrm{P}<0,0001)$ et les rétrécissements malins $(\mathrm{P}<0,0001)$.

CONCLUSIONS : Les facteurs qui influent considérablement sur la durée de la fluoroscopie incluaient l'âge, le diagnostic, l'endoscopiste, ainsi que le nombre et la nature des interventions effectuées. Les patients âgés ayant des calculs biliaires ou un rétrécissement malin étaient susceptibles d'avoir besoin de la fluoroscopie la plus longue. Ces variables pourraient aider les endoscopistes à prédire les interventions qui s'associent à une durée prolongée de la fluoroscopie et à prendre les précautions qui s'imposent.

$\mathrm{E}^{\mathrm{n}}$ ndoscopic retrograde cholangiopancreatography (ERCP) is an important tool for the diagnosis and treatment of disorders of the hepatobiliary system, which uses fluoroscopy for diagnostic and therapeutic purposes. Fluoroscopy performed during ERCP carries a

recognized risk of radiation exposure to patients and staff (1-4). Cumulative high doses of ionizing radiation may have a harmful effect on health (5-7); therefore, limiting radiation exposure to patients and staff is recommended $(8,9)$.

${ }^{1}$ St Paul's Hospital; ${ }^{2}$ Department of Internal Medicine; ${ }^{3}$ Vancouver Hospital, University of British Columbia, Vancouver, British Columbia

Correspondence: Dr Robert Enns, Department of Internal Medicine, St Paul's Hospital, University of British Columbia, 770-1190 Hornby Street,

Vancouver, British Columbia V6K 225. Telephone 604-688-6332 ext 222, fax 604-689-2004, e-mail renns@interchange.ubc.ca

Received for publication February 8, 2011. Accepted February 10, 2011 
Although radiological procedures may only increase the rates of spontaneous malignancy and genetic anomalies by less than $1 \%$ in the general population (10), occupational radiation exposure risks have been more difficult to estimate. Epidemiological research has estimated a $10 \%$ increase in cancer risk with a lifetime occupational exposure of $1 \mathrm{~Sv}$ (11). Postulating a 20\% risk of cancer during a lifetime in North America, the increased cumulative risk, including occupational exposure, would become $22 \%$. One Sievert of radiation from occupational exposure is likely significantly greater than the real effective dose that would be accumulated by an endoscopist with radiation exposure solely from ERCP. Despite the relatively low risk of radiation-induced injury, endoscopists should be aware that all exposure is associated with a cumulative risk. This radiation risk can be significantly reduced with appropriate precautions.

Radiation dose monitoring in patients undergoing diagnostic or interventional radiological procedures has been widely adopted in clinical practice; however, data regarding physician doses during ERCP are limited $(1,3,4,12,13)$. When physician doses were serially measured, endoscopists were found to be exposed to higher levels of radiation than their assistants because the endoscopists were typically closer to the $\mathrm{x}$-ray sources (1). Some factors, such as equipment type (ie, using fixed units versus portable $\mathrm{C}$-arm units), have been shown to reduce radiation dose but are, unfortunately, not easily implemented (14). The radiation beam can be adjusted to use the lowest effective voltage required to produce a clinically useful image, and shielding of patients and staff $(1,13)$ with either permanent (walls or barriers) or portable (drapes or aprons) mechanisms has also been shown to effectively reduce exposure $(1,15,16)$.

Radiation dose has a direct linear relationship with fluoroscopy duration; therefore, limiting fluoroscopy time is one of the simplest and most modifiable methods of reducing radiation exposure during ERCP (15). Reducing fluoroscopy duration may be challenging because nonradiologists may not always be aware of the amount of fluoroscopy time they are using $(15,17,18)$. Additionally, even tracking of radiation dose can be difficult because up to $43 \%$ of radiologists rarely or never wear dosimeters (19), while almost $50 \%$ of endoscopists performing ERCPs never wore a dosimeter (17). Monitoring the length of fluoroscopy time has been implicated in the overall reduction in fluoroscopy times; therefore, the establishment of a monitoring program itself may decrease radiation exposure (20).

Radiation exposure (ie, fluoroscopy duration) during ERCP is theoretically dependent on many factors including the type of procedure (diagnostic or therapeutic) performed, the skill of the endoscopist, the presence of a monitoring program and the presence of altered upper gastrointestinal anatomy (ie, Billroth 2 patients) - all of which may affect the time to perform the study, therefore prolonging fluoroscopy duration $(1,14-16,21,22)$. In general, radiation exposure is greater during therapeutic ERCP than during diagnostic ERCP $(1,3,23)$.

Training has also been found to play a role in fluoroscopy duration and radiation dose during ERCP. Hoskins and Williams (24) found that radiation exposure decreased as the proficiency level of radiology trainees performing fluoroscopic barium studies increased. In interventional radiology, increased levels of physician training have been found to correlate with decreases in patient radiation exposure during fluoroscopic procedures. Uradomo et al (22) showed that radiation exposure during ERCP was directly related to the experience of trainees. Furthermore, as gastroenterology fellows accumulate ERCP experience, the amount of time that patients are exposed to fluoroscopy decreases which, consequently, reduces radiation exposure.

A specific radiological intervention directed at decreasing radiation exposure involves intermittent or pulsed fluoroscopy that substantially reduces the radiation dose without sacrificing image quality (25). Time-limited fluoroscopy, in which $\mathrm{x}$-ray exposure is limited to a set amount of time each time a foot-operated switch is depressed, led to decreased fluoroscopy duration in a prospective study of 100 ERCP procedures (26).
Because radiation exposure is associated with fluoroscopy duration, we sought to further characterize patient, physician and procedural factors that are associated with increased fluoroscopy duration.

\section{METHODS}

A retrospective analysis of 1071 ERCPs performed by five gastroenterologists at two tertiary referral hospitals (Vancouver General Hospital and St Paul's Hospital) in Vancouver, British Columbia, over an 18-month period (February 2006 to August 2007) was conducted.

Information including fluoroscopy time, endoscopist, patient demographics, indication, types of interventions, instruments used, presence or absence of a radiology technician or gastroenterology fellow, and diagnosis was recorded at the time of the procedure. Incomplete forms were assessed by reviewing electronic patient medical records and the missing information was entered. Data were entered into a computer database. Statistical analysis was performed using Stata 10 (Stata Corporation, USA). A significance level of alpha $=0.05$ was set for multivariable linear regression and ANOVA analysis. Ethics approval was obtained from the research ethics board.

\section{Statistical analysis}

Statistical analysis included univariable regression and multivariable analyses. To compare fluoroscopy time with the variables of interest, a natural $\log$ transformation was required because fluoroscopy time is not linear. The following univariable regression equation was used:

$$
\ln (\text { fluoroscopy time })=\beta(\text { variable } 1)+b
$$

Goodness of fit to the model was expressed as $R^{2}$. All endoscopist comparisons were made using Endoscopist 1 as the reference. All 'diagnosis' comparisons were made with 'no pathology found' as the reference. Goodness of fit to the model was expressed as $\mathrm{R}^{2}$.

In the multivariable analysis, the following variables remained significant: age, sex, endoscopist, diagnosis, amount of contrast used, number of instruments used, basket use, biopsies, papillotomy, tritome use and $\ln$ (procedure time). The following variables were dropped due to collinearity: amount of contrast used and $\ln$ (procedure time).

\section{RESULTS}

From the database, 983 of 1071 (92\%) records were appropriate for analysis. Eighty-eight records $(8.2 \%)$ were excluded due to inadequacy of the available data. Fourteen records $(1.3 \%)$ documented failed procedures and were excluded because ERCP duration could not be calculated, leaving 969 records suitable for the final model. The average fluoroscopy duration was $4.66 \mathrm{~min}$ ( $95 \% \mathrm{CI} 4.38 \mathrm{~min}$ to $4.93 \mathrm{~min}$ ). Comparisons between diagnoses were made with 'no pathology found' as the reference (Tables 1 and 2).

From the univariable analysis (Table 3), patient age, diagnosis, amount of contrast, sedation, the type and number of instruments used, and procedures such as dilation, papillotomy and stent insertion were shown to significantly affect fluoroscopy duration. Comparison using $t$ tests determined that the only two diagnoses in which fluoroscopy time was significantly different from the reference diagnosis of 'no pathology found' were common bile duct $(\mathrm{CBD})$ stones $(\mathrm{P}<0.0001)$ and malignant strictures $(\mathrm{P}<0.0001)$.

The endoscopist was found to play an important role in the duration of fluoroscopy (ie, all four endoscopists who were studied had a mean fluoroscopy duration significantly different from the reference endoscopist, when all other variables were held constant). Endoscopist 1 was used statistically as the reference endoscopist. Endoscopists 2, 3 and 5 all had longer average fluoroscopy durations of $1.78 \mathrm{~min}, 1.37 \mathrm{~min}$ and $1.72 \mathrm{~min}$, respectively. In contrast, Endoscopist 4 was found to require, on average, $0.77 \mathrm{~min}$ less fluoroscopy time compared with the reference.

Furthermore, the following procedural variables were found to be significant: the number of procedures performed during ERCP, use of a basket, and procedures including biopsy and papillotomy (all $\mathrm{P}<0.0001)$, and use of a tritome $(\mathrm{P}=0.004)$. 
TABLE 1

Patient, physician and procedural characteristics

\begin{tabular}{lc}
\hline Procedures, $\mathrm{n}$ & 969 \\
Sex, male & $47(487)$ \\
Mean age, years & 54.5 \\
Diagnosis & \\
No pathology found & $20(198)$ \\
Common bile duct stone & $44.8(440)$ \\
Benign stricture & $10.7(105)$ \\
Malignant stricture & $12.4(122)$ \\
Pancreatitis & $5.3(52)$ \\
Bile leak & $2.7(27)$ \\
Ampullary mass & $0.9(9)$ \\
Other & $3(30)$ \\
Endoscopist & \\
Reference endoscopist & $25.6(248)$ \\
Endoscopist 2 & $33.2(322)$ \\
Endoscopist 3 & $5.4(52)$ \\
Endoscopist 4 & $21.0(204)$ \\
Endoscopist 5 & $14.8(143)$ \\
Gastroenterology fellow involved & $0.7(7)$ \\
\hline
\end{tabular}

Data presented as \% (n) unless otherwise indicated

The mean duration (in minutes) of fluoroscopy (with 95\% CIs) for different diagnoses were as follows: CBD stones $(n=443) 5.12$ (3.05 to 4.07); benign biliary strictures $(n=135) 3.94$ (3.26 to 4.63); malignant biliary strictures $(\mathrm{n}=124) 5.82$ (4.80 to 6.85$)$; chronic pancreatitis $(n=49) 4.53$ (3.44 to 5.63); bile leak $(n=26) 3.67$ (2.23 to 5.09); and ampullary mass $(n=11) 3.88(1.28$ to 6.48$)$. When no pathology was seen $(n=195)$, the mean fluoroscopy time was $3.56 \mathrm{~min}$ (95\% CI $3.05 \mathrm{~min}$ to $4.07 \mathrm{~min}$ ).

Comparisons using $t$ tests determined that the only two diagnoses for which fluoroscopy duration was significantly different from the reference diagnosis of 'no pathology found' were CBD stones $(\mathrm{P}<0.0001)$ and malignant strictures $(\mathrm{P}<0.0001)$.

The final multivariable linear regression (Table 4) analysis shows the following variables as having significant impact on fluoroscopy time: age, endoscopist, diagnosis of CBD stones or biliary stricture, number of instruments used and specific therapeutic procedures performed including basket sweep, biopsies, sphincterotomy and tritome use.

\section{DISCUSSION}

In the present retrospective analysis, multiple factors were shown to significantly affect fluoroscopy duration: the endoscopist, patient age, the diagnosis, and the number and nature of procedures performed.

Patient age was directly proportional to the duration of fluoroscopy. Controlling for all other variables, with every one year increase in patient age, fluoroscopy duration increased, on average, by $1 \mathrm{~min}$. This average prolongation of fluoroscopy duration was likely the result of more difficult ERCPs in older patients. (Note: it is not related to therapy because this age group is an independent risk factor outside of the therapies.)

'No pathology found' at ERCP was used as the reference diagnosis. This included a suspected passed CBD stone or diagnostic ERCP, with all other diagnoses compared with this reference diagnosis. A diagnosis of a CBD stone, pancreatitis or malignant stricture required a mean of $1.32 \mathrm{~min}, 1.27 \mathrm{~min}$ and $1.21 \mathrm{~min}$ longer fluoroscopy time, respectively, than the reference diagnosis. In contrast, a diagnosis of benign stricture, bile leak and ampullary mass required a mean of $0.81 \mathrm{~min}$, $0.8 \mathrm{~min}$ and $0.71 \mathrm{~min}$ less of fluoroscopy time, respectively, than the reference diagnosis. Benign strictures are typically not as difficult to traverse compared with some malignant processes.
TABLE 2

Mean fluoroscopy (FI) duration and diagnosis

\begin{tabular}{lcc}
\hline Diagnosis & Mean FI duration, min & 95\% $\mathbf{~ C l}$ \\
\hline No pathology found & 3.56 & $3.05-4.07$ \\
Common bile duct stones & 5.12 & $4.85-5.74$ \\
Benign stricture & 3.94 & $3.26-4.63$ \\
Malignant stricture & 5.82 & $4.80-6.85$ \\
Pancreatitis & 4.53 & $3.44-5.63$ \\
Bile leak & 3.67 & $2.23-5.09$ \\
Ampullary mass & 3.88 & $1.28-6.48$ \\
\hline
\end{tabular}

TABLE 3

Univariable analysis

\begin{tabular}{|c|c|c|c|}
\hline Variable & $\beta^{*}$ & $\mathbf{P}$ & Adjusted $\mathrm{R}^{2}$ \\
\hline \multicolumn{4}{|l|}{ Demographics } \\
\hline Age & 0.006896 & $<0.0001$ & 0.0218 \\
\hline Sex & -0.0827094 & 0.122 & 0.0013 \\
\hline \multicolumn{4}{|l|}{ Endoscopist } \\
\hline Endoscopist 1 (reference) & 1 & - & 0.1085 \\
\hline Endoscopist 2 & 0.0506308 & 0.661 & \\
\hline Endoscopist 3 & 0.3631434 & $<0.0001$ & \\
\hline Endoscopist 4 & 0.0625057 & 0.368 & \\
\hline Endoscopist 5 & 0.7586061 & $<0.0001$ & \\
\hline \multicolumn{4}{|l|}{ Diagnosis } \\
\hline No pathology found (reference) & 1 & - & 0.0493 \\
\hline Common bile duct stones & 0.371646 & $<0.0001$ & \\
\hline Benign stricture & 0.0756588 & 0.456 & \\
\hline Malignant stricture & 0.4667121 & $<0.0001$ & \\
\hline Pancreatitis & 0.2536849 & 0.054 & \\
\hline Bile leak & -0.1599642 & 0.352 & \\
\hline Ampullary mass & -0.1565307 & 0.584 & \\
\hline Other diagnoses & -0.2351758 & 0.152 & \\
\hline \multicolumn{4}{|l|}{ Sedation, amount } \\
\hline Diazemuls & 0.019175 & $<0.0001$ & 0.0430 \\
\hline Demerol & 0.0052584 & $<0.0001$ & 0.0455 \\
\hline Contrast dye & 0.0163121 & $<0.0001$ & 0.1925 \\
\hline \multicolumn{4}{|l|}{ Instruments/procedures } \\
\hline Number of instruments used & 0.2281848 & $<0.0001$ & 0.1094 \\
\hline Balloon & 0.3975574 & $<0.0001$ & 0.0370 \\
\hline Basket & 0.0504418 & 0.338 & -0.0001 \\
\hline Biopsies & -0.2493225 & 0.012 & 0.0049 \\
\hline Brushings & 0.1209979 & 0.132 & 0.0012 \\
\hline Cannula & 0.2705626 & $<0.0001$ & 0.0120 \\
\hline Common bile duct irrigation & 0.2753498 & 0.078 & 0.0020 \\
\hline Dilation & 1.253589 & $<0.0001$ & 0.0307 \\
\hline Guidewire & 0.4748406 & $<0.0001$ & 0.0536 \\
\hline Lithotriptor & 1.509805 & $<0.0001$ & 0.0478 \\
\hline Papillotomy & 0.1855752 & $<0.0001$ & 0.0105 \\
\hline Stent insertion & 0.2740848 & $<0.0001$ & 0.0223 \\
\hline Tritome use & 0.4685202 & $<0.0001$ & 0.0520 \\
\hline In(procedure duration) & 1.002196 & $<0.000$ & 0.4292 \\
\hline
\end{tabular}

*Correlation coefficient

Although one would expect that the fluoroscopy time for patients with a bile leak to be longer than the reference diagnosis due to additional instrumentation, such as sphincterotomy and stent insertion, the decreased fluoroscopy duration of bile leak in the model was not statistically significant. This was most likely due to the small number of patients with this condition. Similarly, an ampullary mass would likely lead to longer fluoroscopy times than a diagnostic ERCP. However, due to the small numbers, this was found to be statistically insignificant. 


\section{TABLE 4}

Multivariable analysis

\begin{tabular}{lrcc}
\hline Variable & $\boldsymbol{\beta}^{*}$ & $\mathbf{P}$ & $\mathbf{9 5 \%} \mathrm{Cl}$ \\
\hline Age & 0.0044953 & $<0.0001$ & 0.0019685 to 0.007022 \\
Sex & -0.0892147 & 0.059 & -0.1816877 to -0.0032582 \\
Endoscopist 1 & 0.5775484 & $<0.0001$ & 0.324038 to 0.8310587 \\
Endoscopist 2 & 0.3125095 & $<0.0001$ & 0.1891555 to 0.4358635 \\
Endoscopist 3 & -0.2570165 & $<0.0001$ & -0.3934315 to -0.1206016 \\
Endoscopist 4 & 0.5444116 & $<0.0001$ & 0.3992895 to 0.6895337 \\
No pathology found & 0.2838052 & $<0.0001$ & 0.1590236 to 0.4085867 \\
CBD stone & -0.2102553 & 0.034 & -0.4042771 to -0.0162335 \\
Malignant stricture & 0.1954469 & 0.038 & 0.0103914 to 0.3805025 \\
Benign stricture & 0.2386551 & 0.041 & 0.0092432 to 0.468067 \\
Pancreatitis & -0.2117636 & 0.163 & -0.5089263 to 0.085399 \\
Bile leak & -0.3411136 & 0.169 & -0.827394 to 0.1451669 \\
Ampullary mass & -0.288652 & 0.046 & -0.5721645 to -0.0051394 \\
Number of procedures & 0.3147136 & $<0.0001$ & 0.261146 to 0.3682812 \\
Use of basket & -0.2628044 & $<0.0001$ & -0.3875972 to -0.1380115 \\
Biopsy performed & -0.4884238 & $<0.0001$ & -0.6735257 to -0.3033218 \\
Papillotomy & -0.2787601 & $<0.0001$ & -0.4021877 to -0.1553325 \\
Use of tritome & 0.2042113 & 0.004 & 0.0634672 to 0.3449553 \\
\hline
\end{tabular}

${ }^{*}$ Correlation coefficient. CBD Common bile duct

Each additional instrument used during an ERCP procedure led to a corresponding increase of $1.37 \mathrm{~min}$ in fluoroscopy duration. Additional instruments used during ERCP would contribute to longer fluoroscopy duration because of the increased number of procedures resulting from the increased complexity and difficulty of these cases. However, the use of a basket was associated with a corresponding decrease of $0.76 \mathrm{~min}$ in the duration of fluoroscopy. Baskets would most often be used for removal of small stones, which may reflect less complexity when compared with cases that do not use baskets (eg, malignant strictures and pancreatitis). Furthermore, the use of endoscopic biopsies led to a corresponding decrease of $0.61 \mathrm{~min}$ in the duration of fluoroscopy. This may reflect that the pathology of interest is seen endoscopically rather than with the assistance of fluoroscopy.

Most of the aforementioned prolongation in fluoroscopy duration likely relates to case complexity. The effect of various measures of case complexity on fluoroscopy time has been previously investigated. In general, radiation exposure was greater during therapeutic ERCP than during diagnostic ERCP $(1,3)$. Uradomo et al (22) found that therapeutic procedures - with the exception of simple stent removal and cyst drainage - were found to have a significantly longer duration of fluoroscopy than diagnostic procedures. Furthermore, most abnormal diagnoses except sphincter of Oddi dysfunction were associated with significantly longer times, as were cases with greater numbers of diagnoses and therapeutic interventions. In another series (1), fluoroscopy duration for therapeutic procedures was approximately $40 \%$ longer than that for diagnostic procedures when performed by the same group of experienced endoscopists. Therapeutic ERCPs were found to be related to longer fluoroscopy times and higher dose-area product and, therefore, radiation doses, than diagnostic ERCPs $(3,23)$.

When all other variables were held constant, statistically significant differences in fluoroscopy duration were found among all of the participating endoscopists. This is likely to be among the largest contributing factors to fluoroscopy duration, and may be due to differences in training, practice patterns and case complexity.

The individual endoscopist is probably the most important contributor to the variance in fluoroscopy duration. It is no surprise that the endoscopist has the most significant role in the amount of fluoroscopy time used during ERCP because it is likely related to multiple factors including technician-controlled fluoroscopy, case complexity, training, experience and individual practice patterns. Because the duration of fluoroscopy of all of the endoscopists was found to be statistically significantly different from the reference endoscopist, it suggests that the variation among the endoscopists is significant. An alternative explanation could be that the fluoroscopy duration of the reference endoscopist was a statistical outlier.

In our study, a gastroenterology fellow was involved in only $0.7 \%$ (seven of 969) of the ERCP procedures. However, the level of training has previously been shown to play a role in fluoroscopy time and radiation dose. While trainee attendance at didactic lectures on radiation protection may not reduce exposure (27), Hoskins and Williams (24) found that radiation exposure decreased as the level of radiology trainees performing fluoroscopic barium studies increased. In that study, experience was measured in years of training, not the number of cases. ERCP also requires substantial training and experience to be performed safely and effectively. Jowell et al (28) assessed the ability of gastroenterology fellows to complete specific technical components of ERCP competently. They found that between 180 and 200 ERCPs were required for the trainees to consistently complete the procedures. In the field of interventional radiology, increased levels of physician training have been found to correlate with decreases in patient radiation exposure during fluoroscopic procedures (24). A recent study by Uradomo et al (22) showed that radiation exposure during ERCP was directly related to trainee experience. In addition, as fellows gain ERCP experience, the amount of time that patients are exposed to fluoroscopy decreases, which reduces radiation exposure. The median fluoroscopy duration was found to decrease by almost 3 min during cases performed by gastroenterology fellows with more experience than 50 previous ERCPs.

Our group recently published a prospective analysis of 388 ERCPs (29), with evaluation of patient, physician and procedural variables associated with prolonged fluoroscopy duration. The current retrospective study was performed before the prospective evaluation, and these relevant findings led to the design and implementation of the prospective study. The present retrospective study involved more than double the number of patients; however, because both had similar results and conclusions (despite being conducted independently), it may also confirm the validity of both studies. In the prospective analysis, factors associated with fluoroscopy duration included endoscopists, stent insertion, lithotripsy, biopsies, use of a needle-knife, guidewire, balloon catheter and involvement of a gastroenterology fellow.

\section{SUMMARY}

In the current retrospective analysis, multiple factors have been shown to significantly affect fluoroscopy duration including age, diagnosis, endoscopist and the number and nature of procedures performed. The only potentially modifiable factor identified is that of the endoscopist who performed the procedure. Elderly patients with complex biliary stones or a malignant stricture are likely to require the longest duration of fluoroscopy.

Further identification of the factors that are related to prolonged fluoroscopy duration may help endoscopists predict which procedures may be associated with radiation so that appropriate precautions (such as additional radiation shielding) can be undertaken, particularly in complex cases. The factors associated with longer fluoroscopy time warrant further investigation.

CONFLICTS OF INTEREST: The authors have no financial disclosures or conflicts of interest to declare.

\section{REFERENCES}

1. Chen M, Van Swearington FL, Mitchell R, et al.

Radiation exposure during ERCP: Effect of a protective field. Gastrointest Endosc 1996;43:1-5.

2. McParland B. A study of patient radiation doses in interventional radiological procedures. Br J Radiol 1998;71:175-85. 
3. Larkin CJ, Workman A, Wright R, et al. Radiation doses to patients during ERCP. Gastrointest Endosc 2001;53:161-4.

4. Buls N, Pages J, Mana F, et al. Patient and staff exposure during endoscopic retrograde cholangiopancreatography. $\mathrm{Br} \mathrm{J}$ Radiol 2002;75:435-44.

5. Brenner DJ, Hall EJ, Phil D. Computed tomography - an increasing source of radiation exposure. N Engl J Med 2007;357:2277-84.

6. Colang JE, Killion JB, Vano E. Patient dose from CT: A literature review. Radiol Technol 2007;25:900-9.

7. Hughes J. CT: Radiation overdose? Radiol Technol 2008;80:92-4.

8. Koenig TR, Wolff D, Mettler FA, Wagner LK. Skin injuries from fluoroscopically guided procedures: Characteristics of radiation injury. Am J Roentgenol 2001;177:3-11.

9. Miller DL, Balter S, Noonan PT, et al. Minimizing radiationinduced skin injury in interventional radiology procedures. Radiology 2002;225:329-36.

10. Hall EJ. Scientific view of low-level radiation risks. Radiographics 1991;11:509-18.

11. Hendee WR. Estimation of radiation risks, BEIR V and its significance for medicine. JAMA 1992;268.

12. Cohen G, Brodmerkel GJ, Lynn S. Absorbed doses to patients and personnel from endoscopic retrograde cholangiopancreatographic (ERCP) examinations. Radiology 1979;130:773-5.

13. Heyd RL, Kopecky KK, Sherman S, Lehman GA, Stockberger SM. Radiation exposure to patients and personnel during interventional ERCP at a teaching institution. Gastrointest Endosc 1996;44;287-92.

14. Johlin F, Pelsang R, Greenleaf M. Phantom study to determine radiation exposure to medical personnel involved in ERCP fluoroscopy and its reduction through equipment and behaviour modifications. Am J Gastroenterol 2002;97:893-7.

15. Campbell N, Sparrow K, Fortier M, et al. Practical radiation safety and protection for the endoscopist during ERCP. Gastrointest Endosc 2002;55:552-7.

16. Cohen R, Aldred M, Paes W, et al. How safe is ERCP to the endoscopist? Surg Endosc 1997;11:615-7.
17. Campbell N, John V, Sparrow K, Ponich T. Radiation safety and protection among ERCP endoscopists. Can J Gastroenterol 2000:48A. (Abst)

18. Geise RA, O'Dea TJ. Radiation dose in interventional fluoroscopic procedures. Appl Radiat Isot 1995;50:173-84.

19. Niklason LT, Marx MV, Chan HP. Interventional radiologists: Occupational radiation doses and risks. Radiology 1993;187:729-33.

20. Vehmas T. Hawthorne effect: Shortening of fluoroscopy times during radiation measurement studies. Br J Radiol 1997;70:1053-5.

21. Van-Husen N, Hogemann B, Egen V, Mehnert C. Radiation exposure in endoscopic retrograde cholangiopancreatography. Endoscopy 1984;16:112-4.

22. Uradomo LT, Lustberg ME, Darwin PE. Effect of physician training on fluoroscopy time during ERCP. Dig Dis Sci 2006;51:909-14.

23. Tsalafoutas IA, Paraskeva KD, Yakoumakis EN, et al. Radiation doses to patients from endoscopic retrograde cholangiopancreatography examinations and image quality considerations. Radiation Protection Dosimetry 2003;106:241-6.

24. Hoskins PR, Williams JR. Influence of radiologist grade on fluoroscopic patient dose. Br J Radiol 1992;65:1119-23.

25. Martin CJ. A review of factors affecting patient doses for barium enemas and meals. Br J Radiol 2004;77:864-8.

26. Uradomo LT, Goldberg EM, Darwin PE. Time-limited fluoroscopy to reduce radiation exposure during ERCP: A prospective randomized trial. Gastrointest Endosc 2007;66:84-9.

27. Vehmas T, Kuosma E. Influence of radiologists' sex and training on fluoroscopy doses during barium enema. Br J Radiol 2001;74:255-8.

28. Jowell PS, Baillie J, Branch MS, Affronti J, Browning CL, Bute BP. Quantitative assessment of procedural competence. A prospective study of training in endoscopic retrograde cholangiopancreatography. Ann Intern Med 1996;125:983-7.

29. Kim E, McLoughlin M, Lam EC, et al. Prospective analysis of fluoroscopy duration during ERCP: Critical determinants. Gastrointest Endosc 2010;72:50-7. 


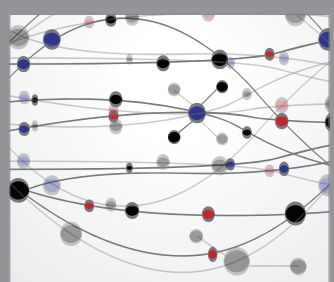

The Scientific World Journal
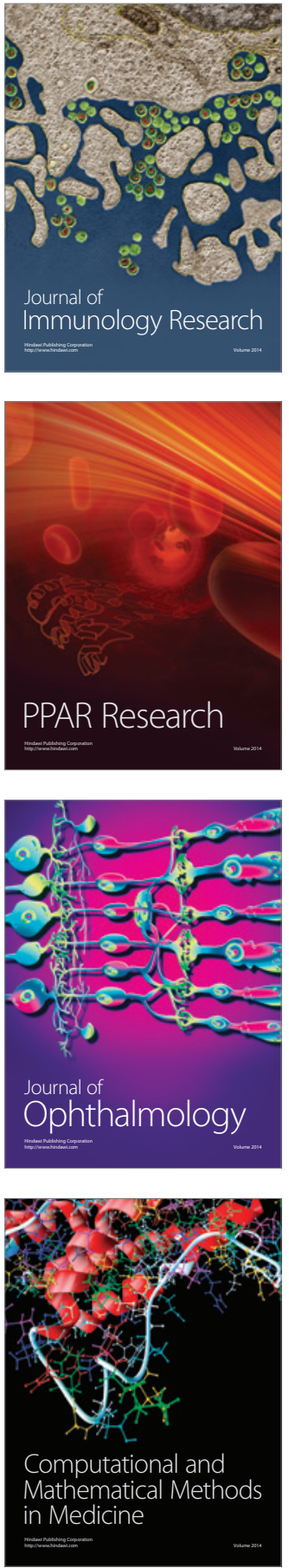

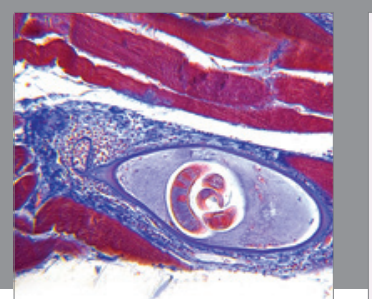

Gastroenterology Research and Practice

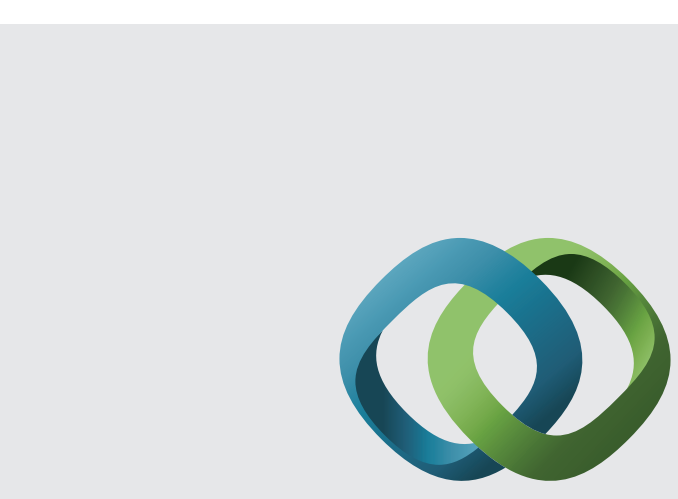

\section{Hindawi}

Submit your manuscripts at

http://www.hindawi.com
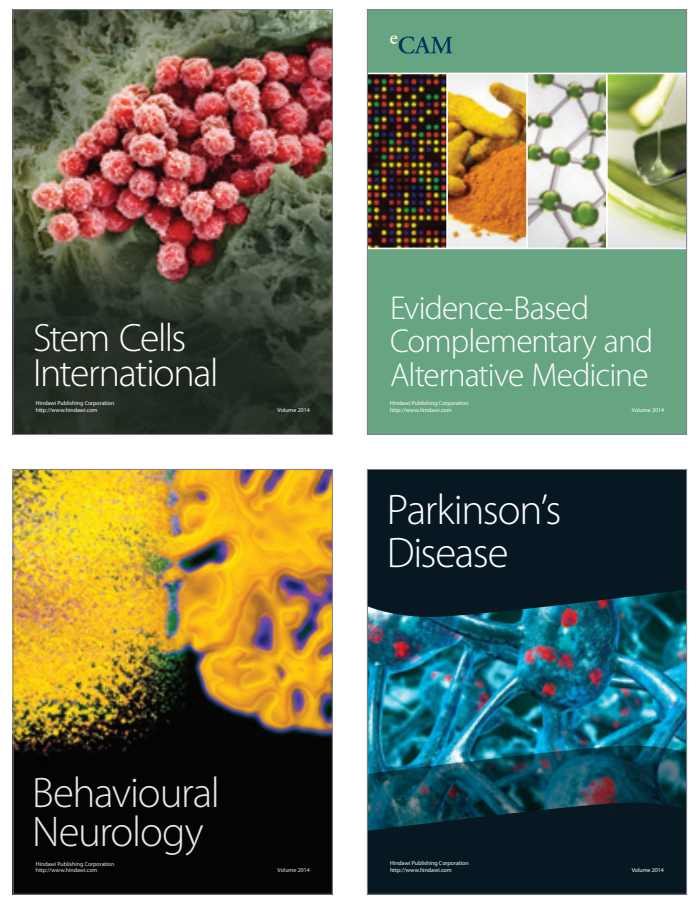
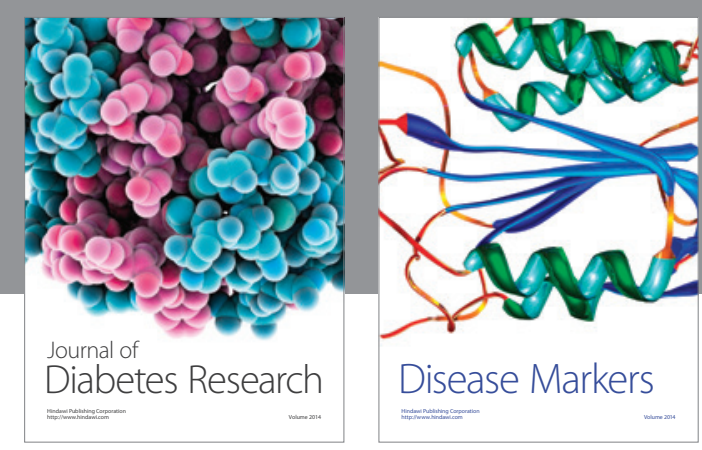

Disease Markers
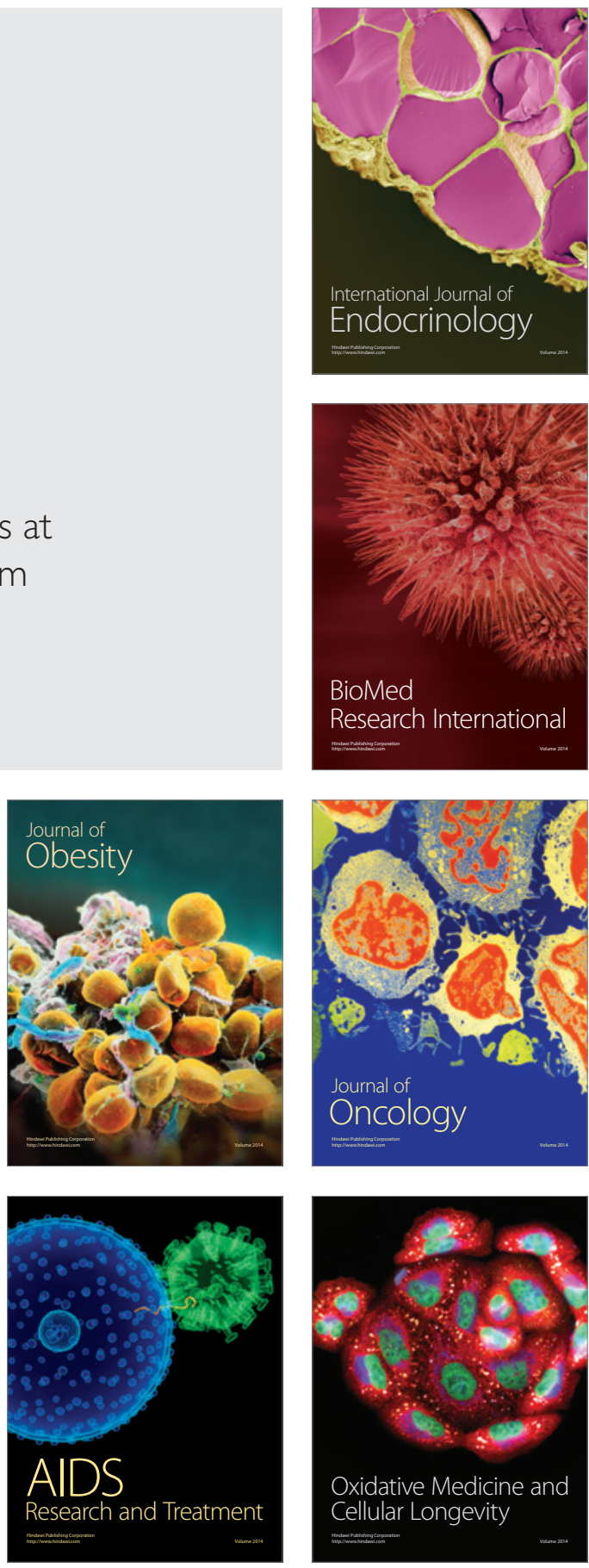